\title{
Redes de prevenção à violência: da utopia à ação
}

\author{
Networks for prevention of violence: from utopia to action
}

Kathie Njaine ${ }^{1}$

Simone Gonçalves de Assis 2

Romeu Gomes 3

Maria Cecília de Souza Minayo ${ }^{2}$

${ }^{1}$ Claves, ENSP, Fiocruz; Uniplac. Av. Brasil 4036 sala 700, Manguinhos. 21040-361 Rio de Janeiro RJ.kathie@claves.fiocruz.br ${ }^{2}$ Claves, ENSP, Fiocruz.

${ }^{3}$ Instituto Fernandes Figueira, Claves, ENSP, Fiocruz.

\begin{abstract}
This article aims to discuss the experience of networks for the protection of people exposed to situations of violence or prevention networks. It is based on the concept created by Castells, who defines the information age. This study is part of the investigation Successful Experiences in the Prevention of Violence, carried out by the Latin-American Center for Studies on Violence Jorge Careli/ENSP-IFF/Fiocruz, in cooperation with the Secretariat for Health Survey of the Ministry of Health. The article analyzes the possibilities and limitations in the construction of networks for the prevention of violence, seeking to understand the sense of actions and movements carried out in networks. The method we used is a case study of two network initiatives in the southern region of the country. In terms of results, in face of the difficulties of working in networks, we found it to be necessary: to break with sectorial and vertical actions; to promote constant communication and interchange of information; to permanently train the professionals and persons involved in the network, incorporating them into the protective and preventive actions; and to promote the participation of wide social sectors. In conclusion, one can affirm that the construction of a protection network involves complex steps, looking to the same problem with new eyes and a new vision for planting solutions.
\end{abstract}

Key words Network, Prevention, Violence, Child, Adolescent
Resumo Este artigo objetiva discutir a experiência de redes de proteção a pessoas em situação de violência ou redes de prevenção. Baseia-se no conceito de rede de Castells, que define a sociedade da informação. O estudo é parte da pesquisa Experiências exitosas em prevenção da violência, realizada pelo Centro Latino-Americano de Estudos de Violência e Saúde Jorge Careli/ENSP-IFF/Fiocruz, junto com a Secretaria de Vigilância à Saúde do Ministério da Saúde. O presente artigo analisa as potencialidades e os limites para a construção de redes de prevenção à violência, buscando apreender o sentido das ações e do movimento em rede. O método utilizado éo estudo de caso de duas iniciativas em rede da Região Sul do País. Os resultados evidenciam que, diante das dificuldades para a atuação em rede, faz-se necessário: romper com a lógica do trabalho setorizado e verticalizado; promover o exercício constante de comunicação e de troca de informações; capacitar permanentemente profissionais e pessoas que se envolvem na rede; incorporar a família nas ações de proteção e de prevenção e promover a participação de amplos setores sociais. Concluindo, pode-se afirmar que a construção de uma rede de proteção demanda etapas complexas, um novo olhar para o mesmo problema e a utopia para plantar soluções.

Palavras-chave Rede, Prevenção, Violência, Criança, Adolescente 


\section{Introdução}

Este artigo propõe-se a discutir a experiência de redes de proteção a pessoas em situação de violência ou redes de prevenção à violência. Parte-se do conceito de "rede", amplamente utilizado na sociedade de informação, definido por Castells ${ }^{1}$ como um conjunto de nós que se encontram interconectados. Esses nós configuram e determinam os fluxos de informação e comunicação existentes entre essas conexões. Abordar o fenômeno da violência e as experiências de rede de proteção ou rede de prevenção significa investigar menos sua configuração e muito mais o quanto ela oferece de potencial de intervir, interromper, tratar ou superar a violência a que estão submetidas milhares de crianças, adolescentes, mulheres, idosos e demais grupos de risco. Sem deixar de abstrair o desenho dessas redes sob o prisma de sua institucionalidade e efetividade, é necessário, em um primeiro momento, tentar assimilar o quanto elas incorporam de parcerias e interconexões que possam viabilizar o encaminhamento, $o$ atendimento e a proteção às vítimas da violência e suas famílias. Em um segundo momento, investigar as diversas possibilidades de desenvolvimento de ações de prevenção.

Segundo Castells ${ }^{1}$, as redes são estruturas abertas que podem se expandir infinitamente, formando novos nós. Para integrar uma rede como uma estrutura dinâmica, é imprescindível que seus integrantes estabeleçam uma ligação entre si, compartilhem valores e objetivos comuns, decodificáveis em um processo de comunicação. Castells ${ }^{1}$, no entanto, alerta que no âmbito da sociedade de informação, a rede também pode ser um instrumento de concentração de poder, como a detenção de conhecimentos tecnológicos com finalidades mercadológicas e relações de trabalho dependentes. Como afirma: Esse é o significado concreto da articulação entre o modo capitalista de produção e o modo informacional de desenvolvimento.

Partindo desta concepção, Frey² incorpora o conceito de capital social, discutindo o uso das novas tecnologias de informação e comunicação para potencializar a participação comunitária na gestão pública local e para promover o desenvolvimento sustentável na emergente sociedade em rede. Sem dúvida, o uso de redes eletrônicas favorece a transmissão de informação em tempo real, estreita a comunicação e a dissemina amplamente. Entretanto, ressalta o autor, essas experiências em redes eletrônicas vêm mostrando a necessidade de projetos que democratizem o acesso a essas novas tecnologias, como a internet.
A "rede" teria esse papel de democratizar a informação, partilhar o poder e a tomada de decisões. Porém, Frey ${ }^{2}$ atenta para o fato de que as comunidades têm que estar preparadas para o uso dessas novas tecnologias, habilitando-se, formando-se do ponto de vista cívico (referindo-se a uma participação política mais efetiva das comunidades na gestão pública) e tornando-se mais autônomas. Esse autor coloca que os desafios de democratização da informação são grandes em uma sociedade com profundas desigualdades. No entanto, aponta que alguns movimentos sociais que hoje dirigem ações específicas voltadas para a inclusão na era digital podem beneficiar comunidades, ajudandoas a enfrentar seus problemas locais. Neste sentido, redes comunitárias, fazendo uso de espaços virtuais de livre acesso, podem ajudar a criação de capital social.

A "rede social" assume então um papel fundamental de aquisição desse capital. A experiência de rede social aponta para as possibilidades e para a importância do desenvolvimento social de determinadas comunidades, do estabelecimento da confiança entre seus membros, do comprometimento, do acesso à informação, às instituições e ao poder de decisão. Alguns estudos de redes sociais têm demonstrado sua relevância para proteção a pessoas ou a grupos que enfrentam problemas de saúde 3,4 .

Na sociedade de informação não é a mera densidade de organizações cívicas que determina a capacidade para ação coletiva. Muito mais importante é a efetividade das redes sociais que unem essas organizações e capacitam-nas a agir de maneira coordenada ${ }^{2}$.

Essas são algumas das possibilidades de uso do conceito de "rede" que servem para fundamentar a compreensão do significado das que aqui são analisadas. Outra perspectiva é a que parte dos processos comunicacionais e da forma como as redes sob essa ótica atendem as pessoas excluídas da atenção. Nesse caso, a comunicação é o fator de agregação e de promoção da igualdade ${ }^{5}$.

Neste texto as organizações sociais, governamentais ou não, se configuram como "nós" de proteção ou de prevenção de violência ou de risco numa rede interconectada. A constituição de uma rede de prevenção à violência exige, quase sempre, um movimento mais intenso, mais contínuo, para integrar diferentes atores e equipamentos sociais (seja através de uma rede informatizada ou não). Além da necessidade de compartilharem um mesmo código de comunicação, o que significa ter a mesma compreensão das diferentes formas de violência, suas causas e conseqüências, é 
preciso que os participantes ajam em sincronia frente à urgente demanda de intervenção.

Não é possível, nesse sentido, formular um conceito único e fechado para "redes de prevenção" ou "de proteção". Essa impossibilidade vem do fato de que são muitas as formas de violência com dinâmicas específicas, e também são múltiplas as experiências dos movimentos sociais que atuam no tema, atendendo à defesa dos direitos da criança, do adolescente e de outros grupos vulneráveis. Visando a contemplar o dinamismo e a pluralidade das iniciativas, investese na atitude profissional e pessoal e na forma de abordar a questão da violência. Por tratar-se de uma questão humana profundamente tocante, tem sido papel dessas redes propiciar o rompimento de silêncios e tabus e a superação de medos e formas de opressão.

\section{Metodologia}

O presente artigo contempla parte de uma pesquisa sobre experiências exitosas de prevenção à violência, aprovada pelo Comitê de Ética em Pesquisa da Escola Nacional de Saúde Pública Sérgio Arouca da Fundação Oswaldo Cruz (ENSP/Fiocruz). Para o estudo especifico, duas redes de promoção e de proteção às vítimas de violência foram visitadas, em Curitiba e em Florianópolis. A primeira delas tem como principal foco ações nas áreas da saúde, educação e assistência social, e a segunda, as atuações do Ministério Público, concatenando vários setores governamentais e não governamentais. Ambas as experiências foram selecionadas a partir de indicações do Conselho Nacional dos Direitos da Criança e do Adolescente.

Foi realizado "estudo de caso"6 para compreender de que forma se constitui uma rede de prevenção da violência e para discutir, de forma mais específica, as potencialidades e limites dessa experiência.

Foram aplicados questionários padronizados contendo informações gerais de cada rede (assuntos que compuseram os questionários), e realizado um grupo focal com profissionais integrantes de cada uma das redes. Trabalhou-se também com "observação de campo". Os registros dessa observação não tiveram um tratamento analítico específico. Eles serviram para contextualizar os depoimentos.

As informações dos questionários, neste trabalho, não são analisadas em termos quantitativos. Figuram no texto, de uma forma descritiva, para melhor caracterizar as redes.
Os dados provenientes dos grupos focais foram trabalhados a partir do "método de interpretação de sentidos", baseando-se em princípios hermenêuticos-dialéticos para a interpretação do contexto, das razões e das lógicas de falas, ações, conjunto de inter-relações, grupos, instituições, conjunturas, dentre outros corpos analíticos ${ }^{7}$. A trajetória analítico-interpretativa partiu de uma leitura compreensiva, passando por recorte dos depoimentos sobre os temas e pela problematização das idéias implícitas no texto, para a busca de sentidos mais amplos que articulavam modelos subjacentes às idéias.

Os dois modelos de rede apresentados a seguir são bem distintos, embora ambos tenham como meta proteger e apoiar a criança, o adolescente e o jovem em situação de risco e violência.

\section{Rede com foco na saúde, educação e assistência social}

A Rede de Proteção à Criança e ao Adolescente em Situação de Risco para a Violência, de Curitiba, foi criada em 2000 com o objetivo de oferecer um atendimento integral a crianças e adolescentes de 0 a 18 anos (incompletos) de idade, de ambos os sexos, bem como a seus familiares. Atende a pessoas de todo o município e encaminha os nãomoradores aos conselhos tutelares dos municípios de origem. Integram a rede diferentes profissionais de várias instituições, apresentadas no quadro 1. A estrutura dessa rede, embora não represente uma hierarquia, é baseada em uma coordenação municipal, coordenações regionais e locais, que desenvolvem ações articuladas entre si ou autônomas. Cada uma das instituições envolvidas atua em parte ou na totalidade do processo de reconhecimento, notificação e acompanhamento dos maustratos e prevenção da violência.

Foram várias as necessidades que motivaram a formação da Rede: complexidade do problema, que exige abordagem multiprofissional e interinstitucional; consciência sobre a alta incidência de maus-tratos contra crianças e adolescentes; necessidade de articulação dos recursos e serviços existentes para o enfrentamento do problema; priorização absoluta da criança e do adolescente nas distintas gestões municipais, cumprindo, assim, as metas do Estatuto da Criança e do Adolescente (ECA); urgência de produção de informações e indicadores que permitissem o conhecimento do problema e o monitoramento das ações; necessidade de elaboração de estratégias de prevenção e enfrentamento à violência. 
Devido ao fato de envolver grande número de profissionais de diversos setores, a implantação da Rede aconteceu de forma paulatina. Teve início numa regional administrativa como projeto-piloto, em 1999. A implantação foi concluída nas oito regionais administrativas em setembro de 2002 . No fim de 2005, eram nove regionais no município, e a Rede passou a ser reconhecida como uma proposta criativa de gestão. Encontra-se em processo de discussão a possibilidade de formalização legal da Rede, por intermédio de aprovação de lei municipal ou decreto.

Não é possível determinar o número de profissionais que integram a iniciativa, pois esta informação é computada apenas nas estatísticas das instituições de origem. Porém, a capacitação para a implantação da rede abrangeu cada regional. Os componentes recebem capacitação por meio de seminários, cursos, grupos de estudos e participações em eventos promovidos por diversas entidades.
A Rede conta com a infra-estrutura física do serviço público municipal (telefones, computadores, salas, fax, veículos e outros recursos). Não existe verba específica para suas atividades. $\mathrm{Na}$ medida do possível, os recursos necessários para a confecção de material gráfico, capacitação e infra-estrutura surgem a partir da solidariedade de diferentes órgãos. A verba referente ao ano de 2005 foi considerada insuficiente para o desenvolvimento pleno das ações de proteção/prevenção pelos gestores da Rede.

O grau de inserção das instituições é freqüentemente desigual, levando ao comprometimento da articulação entre elas. A coordenação municipal e a regional apresentam uma melhor avaliação em relação aos órgãos da rede local, especialmente em relação à assiduidade dos responsáveis pelas organizações nos encontros. Em relação ao apoio mútuo entre os órgãos, à divisão de responsabilidades e ao fluxo de informação, as redes regional e local mostram-se mais incipientes. A rede local,

\section{Quadro 1}

Instituições componentes da Rede de Proteção à Criança e ao Adolescente em Situação de Risco para a Violência, de Curitiba.

Secretaria Municipal de Saúde: desenvolve ações nas unidades de saúde e em nove hospitais, integrando a Rede Local de Proteção.

Secretaria Municipal da Educação: integra a Rede Local de Proteção. Realiza ações preventivas com pais. Desenvolve o Programa Comunidade Escola, que mantém as escolas abertas nos fins de semana para a comunidade, com atividades recreativas e educativas.

Secretaria de Estado da Educação: participa da Rede Local de Proteção.

Fundação de Ação Social: oferece ações da Rede de Proteção Social Básica e Especial: serviço de atendimento a vitimizados em domicílio; abrigos e albergues; plantão social; centro de referência no enfrentamento à violência sexual infanto-juvenil; ações sócio-educativas com famílias; programa de erradicação do trabalho infantil; programas de protagonismo juvenil; programa para adolescente infrator; assistência social básica. Também recebe apoio de organizações não-governamentais (ONGs) que mantêm abrigos, albergues, serviços de plantão social, ações preventivas e outros serviços conveniados.

Secretaria Municipal de Esporte e Lazer: participa com equipamentos, priorizando a inserção de crianças e adolescentes vítimas de violência em atividades esportivas. Conta com o apoio das associações de moradores.

Secretaria Municipal de Abastecimento: introduz crianças e adolescentes participantes da Rede em programas e ações, como inserção em cursos e projetos de alimentação.

Fundação Cultural de Curitiba: contribui com uma rede de serviços e atividades culturais, priorizando a inserção de crianças e adolescentes vítimas de violência nas atividades culturais.

Conselho Tutelar: cumpre as funções definidas pelo Estatuto da Criança e do Adolescente.

Ministério Público: oferece ações das Promotorias da Infância e da Juventude.

Segurança Pública: disponibiliza delegacia estadual especializada na defesa da criança e do adolescente vítima de crime; delegacias, Polícia Militar e Guarda Municipal. 
essencial para a execução das ações, mostra-se a mais fragilizada e a mais sobrecarregada.

A cooperação de grupos de trabalho de diferentes setores locais, que se articulam formal ou informalmente, vem dando algumas respostas aos problemas da violência no interior das próprias comunidades. Por estarem atuando mais próximos das situações de violência, muitas vezes desenvolvem ações autônomas (que podem ficar isoladas) e direcionadas a essa problemática. Neste sentido, o papel que a Rede vem desempenhando é importantíssimo para fortalecer o nível local, as comunidades e os pequenos grupos que se engajam nessa tarefa.

A Rede não conta com estatísticas e registros centralizados que descrevam os tipos de ação e meios de proteção ou de prevenção realizados a favor das crianças e adolescentes e de seus familiares. As coordenações regionais, sim, dispõem de registros em atas ou em memórias de reuniões, embora não sistematizados. A ficha de notificação da violência tem sido utilizada para acompanhar os casos e subsidiar a construção de um "banco de dados sobre a situação de violência contra crianças e adolescentes" no município.

A prática de avaliação dos resultados das ações de proteção e de prevenção realizadas na Rede ainda não está estabelecida, o que é uma pena, pois impede dimensionar e apreciar devidamente seus resultados. A percepção dos membros que compõem a iniciativa é de aumento contínuo de qualidade nas práticas de prevenção e de atendimento às vítimas e suas famílias.

A partir das limitações atualmente existentes, os componentes da Rede reconhecem as seguintes necessidades a serem atendidas no futuro: 1) capacitação permanente e sensibilização das equipes multiplicadoras, por regional; 2) estruturação de serviço de orientação e apoio a famílias que enfrentam situação de violência domiciliar; 3 ) melhor integração com os conselhos tutelares; 4) avanço no trabalho intersetorial e integrado; 5) ampliação das ações da rede para o setor privado da educação e saúde; 6) informatização da ficha de notificação obrigatória; 7) formalização legal da Rede; e 8) empenho para incluir o atendimento às vítimas de violência no conjunto das prioridades dos serviços.

Uma premissa importante trazida pela Rede de Curitiba para essa nova concepção de trabalho integrado e intersetorial é o entendimento de que essa tarefa é uma "constante construção". A experiência mostra que a implantação de uma rede de proteção não exige grandes investimentos do setor público ou privado, mas, acima de tudo, uma mudança de olhar e uma visão mais atenta dos profissionais, familiares e outros responsáveis para as crianças e adolescentes, visando a prevenir, orientar, diagnosticar e prestar assistência por meio dos equipamentos legais. Nesse sentido, não necessariamente se deve criar novos serviços ou programas (a não ser que, por algum motivo, esses precisem ser reorganizados), mas integrar os já existentes, contando com pessoas sensibilizadas e comprometidas.

\section{Rede com enfoque no Ministério Público}

Esta rede, em Florianópolis, foi criada em outubro de 2004, liderada pelo Ministério Público Estadual. Nos nove meses seguintes à sua criação, foram incluídas as 16 regionais do estado, totalizando 295 municípios envolvidos, incluindo a capital. Sua construção foi motivada pela constatação do alto índice de maus-tratos registrado pelos conselhos tutelares. $\mathrm{O}$ alvo das ações é a população formada por crianças e adolescentes até 18 anos, de ambos os sexos.

A Rede foi formalizada por meio de termo de cooperação assinado por várias instituições, criando, no Estado de Santa Catarina, o instrumento "Aviso Por Maus-Tratos Contra Criança ou Adolescente" (APOMT), que se encontra em fase de instalação. Diferentemente do município de Curitiba, onde o setor saúde teve um papel fundamental de disseminador, em Florianópolis o Ministério Público tem sido o agregador de outras instituições na discussão da Rede.

A concepção central que norteia a construção da Rede de Santa Catarina é a do sistema de informação capaz de contribuir com dados estratégicos para todas as instituições envolvidas sobre a violência que acomete crianças e adolescentes. $\mathrm{O}$ sistema de informação é considerado instrumento potencializador na definição de ações de prevenção, uma vez que o acesso a informações organizadas e fidedignas pode subsidiar políticas públicas direcionadas aos problemas locais.

Uma campanha - desenvolvida por uma empresa de comunicação na mídia eletrônica e veiculada ao longo de dois anos, abordando o tema da violência contra crianças e adolescentes e sua prevenção - promoveu a sensibilização para o tema. A partir dessa campanha, o Ministério Público vem mobilizando parceiros para o trabalho em rede. As instituições envolvidas nas atividades de proteção e de prevenção encontram-se no quadro 2.

Além dessas instituições parceiras, a gestão da APOMT também menciona a participação dos seguintes órgãos na Rede: Fundação Mauricio 
Sirotsky Sobrinho, Conselho Estadual da Criança e Adolescente, Sindicato dos Estabelecimentos Particulares de Ensino; Sociedade Catarinense de Pediatria, entre outros. Entretanto, não são especificadas as ações desenvolvidas por esses órgãos, na parceria com a Rede.

A Rede possui uma comissão gestora e técnica composta por funcionários públicos dos diferentes órgãos. A capacitação sobre o tema da violência e a sensibilização para a necessidade do atendimento em rede é oferecida a todos os profissionais que participam do lançamento do programa em cada regional.

À Rede são disponibilizados telefones, fax, computadores, salas e viaturas das instituições que participam do convênio. Não existe verba específica para manter as atividades dessa iniciativa, $\mathrm{o}$ que a torna dependente dos recursos existentes nos órgãos conveniados.

A articulação entre as instituições parceiras foi avaliada de forma positiva pelo grupo gestor da Rede no que concerne a: freqüência a reuniões, assiduidade dos responsáveis pelas atividades, apoio mútuo entre os programas, divisão de responsabilidades e referência e contratransferência de informações.

Dentre as limitações apontadas pela gerência da Rede em relação ao desenvolvimento das ações de prevenção destacam-se: a publicação ainda insuficiente do material de apoio pedagógico; escassa divulgação da iniciativa pela mídia; falta de uma equipe permanente especializada no atendimento aos casos de maus-tratos em cada município para o oferecimento de suporte técnico aos demais profissionais.

A Rede ainda conta com muitas possibilidades de ação a serem exploradas. Estão previstos, por exemplo, lançamento da proposta nos $293 \mathrm{mu}$ nicípios: em cada escola, em cada posto de saúde, nas delegacias, nos conselhos tutelares, nas promotorias de Justiça, nos programas de atendimento, no Conselho Municipal dos Direitos da Criança e do Adolescente de cada um dos municípios. Até o momento em que a avaliação se encerrou, as atividades de capacitação e os lançamentos da proposta haviam sido realizados apenas em nível regional.

Os resultados das ações de proteção e de prevenção coordenadas pela Rede ainda não são passíveis de serem avaliados, pois o programa se encontra em fase de implantação. Ainda não existem estatísticas de crianças e adolescentes que receberam ações de proteção ou de prevenção patrocinadas pela Rede. Embora haja a proposta de atendimento às famílias das crianças e adolescentes víti- mas de violência, não existem dados a esse respeito. Estão em fase de implementação vários formulários que foram criados com a finalidade de sistematizar as informações em cada uma das instituições participantes: segurança pública, sistema de saúde, escola, conselho tutelar, programas de atendimento.

No futuro, todos os profissionais que participam da Rede, nos casos de suspeita ou confirmação de maus-tratos, utilizarão estes formulários que serão remetidos ao Conselho Tutelar. Por sua vez, essa entidade os remeterá ao promotor de Justiça, que os lançará no banco de dados. Os promotores de Justiça da Infância e Juventude alimentam um banco de dados online que proporciona relatórios periódicos. Estes serão disponibilizados no site do Ministério Público do Estado de Santa Catarina. Os componentes da rede pretendem que esta seja a forma de registro estatístico das ações efetuadas.

O trabalho em rede que se dá, sobretudo, por intermédio do fluxo de informação da denúncia da violência ainda tem que se aperfeiçoar, no sentido de o Estado prover condições mais apropriadas para o funcionamento da proposta. São necessários maior apoio financeiro, menos burocracia no fluxo da informação, mais integração entre as instituições responsáveis por crianças e adolescentes, dentre outras ações que possam fazer crescer a rede no estado.

Nos documentos de implantação encontramse alguns princípios importantes de serem levados a termo, embora muitos deles ainda estejam longe de serem efetivados. Um deles trata da necessidade de se lidar com agressores por meio de tratamento e orientação, e não apenas de punição. Nesse documento, também é indicada a importância de se abordar a família, no sentido de protegê-la. Um terceiro aspecto de extrema relevância que tem tido prioridade é o de capacitação de profissionais.

$\mathrm{Na}$ época em que se desenvolveu a pesquisa de campo, a rede estava no estágio de implantação e de capacitação de seus membros para a notificação de maus-tratos cometidos contra crianças e adolescentes e para os encaminhamentos de tal tipo de notificação.

\section{A construção de redes de prevenção - outras experiências}

Ainda não existe no País um mapeamento consolidado das experiências em rede que estão em curso nas diversas regiões, embora se saiba que, mesmo em diferentes níveis de construção, muitas delas vêm conseguindo obter alguns êxitos significativos 
Secretaria de Estado da Saúde: responsabilizou-se por integrar o programa APOMT e as normas para a sua execução a uma portaria sobre o tema já existente no estado. Comprometeu-se a: encaminhar cópia da portaria e do formulário do programa APOMT a todas as unidades de saúde; oferecer apoio técnico e capacitação de funcionários para o correto atendimento e encaminhamento das vítimas de maus-tratos; designar técnicos para compor a equipe técnica responsável pela sensibilização e capacitação dos parceiros executores nas regionais. Comprometeu-se também com a Política Nacional de Redução da Morbimortalidade por Acidentes e Violências, propondo-se a garantir a promoção da adoção de comportamentos e de ambientes seguros e saudáveis, a sistematização, a ampliação e a consolidação do atendimento pré-hospitalar; a proporcionar a assistência interdisciplinar e intersetorial às vítimas de violência e a estruturar e consolidar o atendimento voltado à recuperação e à reabilitação.

Secretaria de Estado da Segurança Pública e Defesa do Cidadão: comprometeu-se a instituir o programa APOMT por portaria em todas as delegacias de polícia e demais órgãos afins, bem como a inserir normas para sua execução. Também prevê: apoio técnico e capacitação de funcionários; comparecimento de profissional às unidades de saúde para efetuar registro de ocorrência de crime sexual e de lesões corporais graves, evitando o deslocamento da vítima à delegacia de polícia; realização de exames de lesão corporal ou de conjunção carnal na unidade de saúde onde o problema foi diagnosticado, pelo médico legista do IML; adequação das estruturas físicas das delegacias de polícia para garantir privacidade no atendimento às vítimas de crimes sexuais e de maus-tratos; disponibilização de técnicos para compor a equipe que fará a sensibilização e a capacitação dos parceiros executores nas regionais; inserção do tema na carga curricular de direitos humanos nos cursos de formação e de capacitação das instituições policiais.

Secretaria de Estado do Desenvolvimento Social, Urbano e do Meio Ambiente: responsabilizou-se por socializar o programa em reunião de gerentes regionais de desenvolvimento social, organizando com eles processos de multiplicação nas regiões; prever horas/aula sobre essa temática na formação de profissionais que atuam no atendimento a crianças e adolescentes; oferecer apoio técnico aos profissionais com atuação na área; fortalecer os programas já existentes de apoio às crianças e aos adolescentes vítimas de maus-tratos e suas famílias e fomentar a criação dos mesmos em municípios em que ainda não existem.

União Nacional dos Dirigentes Municipais de Educação do Estado de Santa Catarina: responsabilizou-se por repassar aos prefeitos uma cópia do APOMT e por conclamar seus associados a apoiar o programa.

Ministério Público do Estado de Santa Catarina: por intermédio do Centro de Apoio Operacional da Infância e Juventude, comprometeu-se a instruir os promotores de Justiça que atuam nas áreas Criminal e da Infância e Juventude de todo o Estado de Santa Catarina; a conclamar sucessivamente os promotores de Justiça criminais e da Infância e Juventude de cada uma das regiões para lançamento e debate do programa na respectiva região; processar as informações recebidas de todos os parceiros relativas aos "avisos por maus-tratos", organizando-as em bancos de dados e divulgando-as em relatórios semestrais.

Fórum Catarinense pelo Fim da Violência e da Exploração Sexual Infanto-Juvenil: assumiu as seguintes atribuições: ampliar a capacitação; integrar seus membros ao programa; acompanhar o envio de cópia do APOMT aos coordenadores regionais e profissionais para que atuem como multiplicadores de ações de prevenção das várias formas de violência.

Associação Catarinense de Conselheiros Tutelares: propôs-se a acompanhar o envio de cópia do APOMT a todos os conselhos tutelares; incluir a temática na capacitação de conselheiros; conclamar seus associados a apoiar e a participar da divulgação e da avaliação da rede. 
no campo da prevenção da violência em geral e da proteção a pessoas em situação de violência.

As múltiplas e muitas vezes improváveis possibilidades de parceria são características das redes, principalmente entre Estado, setor privado e sociedade. Um exemplo de ação integrada encontra-se em São Paulo: o Centro de Referência às Vítimas de Violência (CNRVW) do Instituto Sedes Sapientiae, que tem como um dos seus objetivos a criação de redes de proteção a pessoas em situação de violência doméstica. Para isso, a equipe do CNRVV, com recursos financiados pelo setor público ou privado, vem formando pólos em diversas comunidades da cidade, onde se reúnem pais, educadores, crianças e jovens. Nesses ambientes, há oficinas de dramatização, palestras e jogos de interação. Neles, os participantes têm oportunidade de refletir sobre a violência, suas causas e danos, integrando profissionais responsáveis por crianças e adolescentes como diretores de escolas, conselheiros tutelares e agentes de saúde. Também o trabalho e as dificuldades de cada um se tornam conhecidos e compartilhados.

O princípio de ação nesses pólos é o despertar da consciência dos direitos e das responsabilidades dos cidadãos, sobretudo em relação à mudança de realidade de violência que marca a vivência de muitas famílias. Para tal, a sensibilização, a promoção da auto-estima, a capacitação para que se tornem agentes dessa mudança, a otimização dos recursos locais e o fortalecimento de uma rede de atendimento são ações prioritárias que dão visibilidade às pessoas que crescem em conjunto.

O CNRVV desenvolveu uma metodologia para a criação de pólos, sistematizando essa importante iniciativa. A rede atua em diversas etapas de prevenção: identificação e reconhecimento dos sinais de risco, notificação, acompanhamento da criança, do adolescente e da família, apoio legal para quem necessita. E quando é possível, atende também o agressor.

O Projeto Resgate Cidadão, também criado pelo CNRVV, voltado para a potencialização dos recursos locais - ainda que escassos -, Trabalha com a inclusão social de crianças e adolescentes que vivem em comunidades pobres. Esse projeto cria uma rede de prevenção à violência num dos bairros de São Paulo. Ele mobiliza recursos locais de saúde, de assistência social, comunitários, esportivos e educacionais. Sua meta principal é formar os adolescentes para serem agentes multiplicadores de ações de prevenção da violência e promoção da cidadania ${ }^{8}$.

\section{Conclusões}

Pretendeu-se com este trabalho apresentar um movimento promissor e crescente de atuação em "redes" voltadas especificamente para promover a proteção e prevenir a violência contra a criança e o adolescente, tornando este problema uma causa pública e compartilhada pelos mais diferentes atores governamentais, ONGs e empresas privadas. Tais iniciativas fazem uma inflexão positiva, quebrando a invisibilidade, a conivência e o silêncio que permeiam a maioria das formas de violência desde a infância. O trabalho de desnaturalizar a prática da violência implica em causar "rachaduras" ou tombar muitos pilares que sustentam valores culturais arcaicos, entranhados na história brasileira e que perpetuam mitos prejudiciais à infância e a adolescência. Esses mitos, preconceitos e tratamentos discriminatórios tendem a se reproduzir, se não houver uma intervenção civilizatória, apresentada, no caso brasileiro, pelo ECA. As redes, como forma de atuação, não só têm a tarefa de proteger em larga escala, mas também de fazer com que a violência, suas causas e conseqüências sejam reconhecidas como um problema que afeta os indivíduos e a coletividade. Ainda contribuem para mostrar que o mal da violência contra crianças e adolescentes é abominável, mas tem cura.

Importante ressaltar que a estratégia de "rede" se coaduna com a forma gerencial mais atual das sociedades pós-industriais, como evidencia Castells ${ }^{1}$. Ao cuidar do saudável crescimento e desenvolvimento desses pequenos cidadãos, o trabalho em rede torna pública e politizada uma problemática típica da sociedade patriarcal e adultocêntrica, que só pode ser vencida pela solidariedade e complementaridade de parcerias, de forma que cada parte cumpra seu papel e se conecte com as outras.

A análise realizada evidencia que para a eficácia da ação em rede são necessários alguns requisitos que se constroem no processo: horizontalidade dos setores; representação de diversas instituições por intermédio de seus líderes; corresponsabilidade de trabalho; divisão de recursos e informações; autonomia das instituições parceiras para decidir, planejar, executar ações que visem à coletividade; capacidade de incorporar novas parcerias e permitir a saída de instituições ou pessoas; e sustentabilidade. Estes aspectos por si sós não garantem um movimento exitoso, mas são ao mesmo tempo pré-requisitos e parâmetros de ação.

Os problemas que mais prejudicam o trabalho em rede são: disparidade de compreensão; divergências políticas; vaidades pessoais; conflitos de pa- 
péis entre as entidades participantes; rotatividade dos profissionais que atuam nas instituições parceiras; diferentes ritmos de trabalho; e incompatibilidade de quadros referenciais de vida.

Outra dificuldade comum às redes analisadas é a incorporação da família nas ações de proteção e de prevenção, iniciada no momento do atendimento da criança e do adolescente vítimas de violência. Embora, tanto a rede de Curitiba quanto a de Florianópolis informem realizar atendimento à família, os gestores e técnicos reconhecem a dificuldade e as deficiências desse atendimento. Freqüentemente, apenas a mãe é inserida na ação e de forma irregular. A inclusão da família nos processos de transformação cultural é um grande desafio para as redes, da mesma forma como tem se mostrado em outros tipos de serviços que atendem pessoas em situação de violência ${ }^{9}$.

Em função dos requisitos e dos problemas conclui-se que a construção de redes, por ser uma estratégia de ação nova, exige investir em capacitação e incentivo dos participantes, para que todos possam se comunicar de forma ágil e clara. Esse é um grande e permanente desafio a ser enfrentado, que requer a participação de amplos setores sociais como, por exemplo, a mídia, a educação, a saúde e os movimentos comunitários. Trata-se de prover informação que possibilite a transformação, não somente por meio da aquisição de conhecimento formal sobre a violência, mas, principalmente, por intermédio da promoção da cidadania como forma de enfrentamento da violência. Os exemplos de capacitação assinalados neste artigo mostram uma iniciativa em processo, em que o conhecimento e o envolvimento de todos os parceiros fazem a diferença e resolvem o nó da tão propalada "intersetorialidade".

O estudo evidencia também a necessidade de investimento em acompanhamento externo e avaliação, pari passu com a auto-avaliação. Os dois exemplos apresentados mostram redes que têm ampla base de recursos governamentais. Várias outras iniciativas são calcadas em iniciativas de abrangência local, concatenando ONG e comunidades que, unidas, pressionam e demandam a inclusão dos serviços governamentais. Há também propostas levadas a cabo por empresas privadas, na linha do ethos da responsabilidade social. Mas o reconhecimento oficial ou a formalização do trabalho em rede não são suficientes para manter as interconexões. Muitos profissionais entrevistados na pesquisa citada neste estudo consideram, com Mattelart et al. ${ }^{5}$, ser importante que as próprias comunidades reconheçam o papel das parcerias em conexão. Nesse sentido, a visibilidade dos equipamentos do Estado nas comunidades, fazendo-se presentes e atuantes, tem sido fundamental para que as pessoas confiem nas instituições e em sua ação. Por sua vez, a influência das instituições que compõem as redes é decisiva no processo de evidenciar para os poderes locais, municipais, estaduais, federal e internacional ${ }^{10}$ o quão prejudicial é a violência e suas formas de manifestação.

Concluindo, pode-se afirmar que a construção de uma rede de proteção demanda etapas complexas, um novo olhar para o mesmo problema, a utopia para plantar soluções e a superação do modo de trabalho setorizado e verticalizado. Desafiar essas dificuldades estimula o desejo de muitos profissionais envolvidos na criação dessa iniciativa, e o resultado, sem dúvida nenhuma, é a transformação de todos os que participam em pessoas mais solidárias e mais eficazes nas atividades específicas que desempenham. O nó que se cria entre as várias colaborações as transforma em pessoas maiores que si mesmas.

\section{Colaboradores}

K Njaine, SG Assis, R Gomes e MCS Minayo participaram igualmente de todas as etapas da elaboração do artigo. 


\section{Referências}

1. Castells M. A sociedade em rede. São Paulo: Paz e Terra; 2000.

2. Frey K. Desenvolvimento sustentável local na sociedade em rede: o potencial das novas tecnologias de informação e comunicação. Rev. Sociol. Polít. 2003; 21:165-85.

3. Andrade GRB, Vaitsman J. Apoio social e redes: conectando solidariedade e saúde. Rev C S Col 2002; 7(4):925-34.

4. Marteleto RM. Análise das redes sociais: aplicação nos estudos de transferência da informação. Ciência da Informação 2001; 30(1):71-81.

5. Mattelart A, Mattelart M. História das teorias da comunicação. São Paulo: Edições Loyola; 2000.

6. Becker HS. Método de pesquisa em ciências sociais. São Paulo: Hucitec; 1993.

7. Gomes R, Souza ER, Minayo MCS, Silva CFR. Organização, processamento, análise e interpretação de dados: o desafio da triangulação. In: Minayo MCS, Assis SG, Souza ER, organizadoras. Avaliação por triangulação de métodos: abordagem de programas sociais. Rio de Janeiro: Fiocruz; 2005. p. $185-221$
8. Fundação Abrinq. O Fim da omissão - A implantação de pólos de prevenção à violência doméstica. Prêmio Criança 2002. São Paulo: Fundação Abrinq; 2002.

9. Deslandes SF, Assis SG, Njaine K, Ximenes LF, Gomes R, Cabral CA, et al. Famílias: parceiras ou usuárias eventuais? Análise de serviços de atenção a famílias com dinâmica de violência doméstica contra crianças e adolescentes. Rio de Janeiro: Claves/ENSP/Fiocruz; Brasília: Unicef; 2004.

10. OMS. Relatório mundial sobre violência e saúde. Genebra: Organização Mundial da Saúde; 2002.

Artigo apresentado em 6/03/2006

Aprovado em 30/03/2006

Versão final apresentada em 7/04/2006 